\title{
Ethnic bias in the application of the Mental Health Act 1983
}

\author{
Kalpana Dein, Paul Simon Williams \& Simon Dein
}

\begin{abstract}
There is evidence pointing to a bias in the application of the Mental Health Act 1983 (which is in force in England and Wales). One study found that Black people on in-patient units were four times more likely to have been compulsorily admitted than White people. Furthermore, it has been shown that compulsory admissions to secure units are 2.9-5.6 times higher for Black than for White patients. Any understanding of this bias necessitates an examination of the attitudes of mental health professionals towards Africans and African-Caribbeans. Here we discuss possible contributory factors and examine a number of initiatives that have been instituted in order to tackle this problem.
\end{abstract}

A comprehensive review by Sharpley et al (2001) concluded that African-Caribbean people resident in England were at a higher risk of developing an illness that meets the operational criteria for schizophrenia than: (a) the populations in their countries of origin in the Caribbean; and (b) the White, indigenous population. However, hallucinations and paranoid ideas conventionally considered as pathognomonic of psychosis may be more common among African-Caribbean people than the remainder of the population in England. This raises the question of whether the threshold for qualifying for a diagnosis of schizophrenia should be set higher for the African-Caribbean population. AfricanCaribbean individuals who are diagnosed as having schizophrenia show a greater affective component to their illness than do their White counterparts. Some evidence (Sharpley et al, 2001) also suggests that schizophrenia in this population is associated with a more relapsing and remitting course, with more social disruption and fewer negative symptoms than in White patients. This pattern of illness conforms more, in some ways, to schizoaffective psychosis than to chronic schizophrenia.

The excess of psychosis in the African-Caribbean population in the UK is at odds with incidence rates reported in the Caribbean countries. The incidences of schizophrenia in Jamaica, Trinidad and Barbados have been found to be similar to the rate for the White population in England (Sharpley et al, 2001).

Although psychosis is generally thought to be partly under genetic influence, the apparent excess in the African-Caribbean population cannot be explained exclusively in genetic terms or by the selective migration of individuals who later develop psychosis. The frequency of schizophrenia in the siblings of second-generation African-Caribbeans with schizophrenia implies the operation of environmental factors on individuals from vulnerable families.

What could these environmental factors be? Neurodevelopmental hazards appear, if anything, to be less common in African-Caribbean than in White patients diagnosed as having schizophrenia. The significance of cannabis misuse is not yet resolved. There is emerging evidence that cannabis use in adolescence is related to the later onset of schizophrenia (Caspi et al, 2005), an effect which might be moderated through a functional polymorphism in the catechol-O-methyltransferase (COMT) gene. Sociocultural factors have been the subject of much untested speculation. More single-parent families, poorer school achievement, high unemployment, more solitary living and less social support among the African-Caribbean community have all been blamed, and could contribute to a lower threshold for social disruption.

It is important to ascertain the causes of the high incidence of psychosis among African-Caribbean people living in England because it represents a considerable burden on an already deprived population. If we could understand the factors that drive it, then we might be able to initiate preventive measures. Furthermore, we might also learn more

Kalpana Dein is a locum consultant forensic psychiatrist working for Essex Forensic Mental Health Service (Runwell Hospital, Wickford, Essex SS11 7XX, UK. Email: kalthomas@yahoo.co.uk). She is an executive editor for World Cultural Psychiatry Research Review. Paul Simon Williams is a consultant forensic psychiatrist working for North London Forensic Service. He has interests in outreach services and the interaction between culture and mental health. Simon Dein is an academic psychiatrist at University College London. He has written on religion and health and is the Course Director of a Masters degree in culture and health. 
about the aetiology of psychosis in general. Already the preliminary findings are intriguing in that they point towards social and cognitive factors, areas of research into psychosis that have been neglected in recent years.

The $Æ S O P$ study of psychiatric patients (Morgan et al, 2005) found that African-Caribbeans in general, and African-Caribbean men in particular, were significantly more likely to be compulsorily admitted than White British patients, as were Black African patients. As this study was conducted among patients with a first episode of psychosis, these findings suggested that factors were operating at or prior to first presentations to increase the risk of compulsory admission among African-Caribbean and Black African patients.

Thornicroft et al (1998) examined the case notes of 500 patients with psychosis in the UK. Over $50 \%$ of these had been admitted under the Mental Health Act 1983 at least once in the course of their illness. Other studies have shown that African and African-Caribbean people who have a psychotic illness and who live in London are between four and eight times more likely to be detained than their White counterparts (Audini \& Lelliott, 2002).

The consultation document Inside Outside (Sashidharan, 2003) and other research show that people from Black and minority ethnic groups are more likely to experience an aversive pathway to mental health services, higher rates of compulsory admission to hospital, a greater involvement of the legal system and forensic psychiatrists, and higher rates of transfer to medium and high secure facilities.

Thus there is overwhelming evidence suggesting increased rates of compulsory detention for patients from some minority groups. How can this finding be explained? Box 1 lists a few potential contributory factors.

\section{Potential contributory factors}

\section{Defects of research methodology}

Under-enumeration of Black people in the general population is a drawback shared by all the studies that report a higher percentage of Blacks among people detained under the Mental Health Act 1983 (Harrison, 2002). Ethnic data on detained patients have been monitored by the Mental Health Act office since April 2002. There is still, however, a high percentage of cases recorded as 'ethnicity not known' (Aspinall, 2006). Harrison (2002) pointed out that there are multiple, even contentious methods of defining ethnicity. Most studies do not identify the subdivisions of what is broadly classified as Black or Black African-Caribbean. It has been shown that
Box $1 \mathrm{~A}$ few factors that might contribute to the finding of over-representation of detained African-Caribbean patients

- Methodological defects in research

- Apparent increase in the prevalence of psychosis

- Adverse pathways to care

- Cultural misunderstanding

- Racism in psychiatry

among patients of Caribbean origin, Jamaicans have the highest annual admission rates to British hospitals (Bhui et al, 2003).

A recent study has highlighted the importance of distinguishing between first and subsequent presentations to services, which previous studies did not take into account (Morgan et al, 2005). Despite the limitations of research methodology, the majority of papers provide strong evidence for a relative excess of compulsory admissions for Black people (Bhui et al, 2003).

\section{Perceived risk}

One initial explanation proposed to account for the high proportion of compulsory admissions among African-Caribbeans was that for some reason they presented as more disturbed than White patients (Rwegellera, 1980); i.e., they were actually more violent, or they were perceived to be so. Researchers have differed in what they define as indicators for the severity of disturbance: challenging behaviour, violence and poor insight, as well a perceived risk (Morgan et al, 2005). Pipe et al (1991) found that young Black men were considered more threatening and disturbed; this fact may have contributed to the increased rates among this group. The $Æ S O P$ study (Morgan et al, 2005) found that neither diagnosis nor perceived risk accounted for the increased detention of African-Caribbean men or Black African patients.

\section{Stigma}

It has been postulated that Caribbean communities stigmatise mental illness more heavily than other groups. This in turn might cause African-Caribbean families to interpret early symptoms and disturbed behaviour in criminal rather than medical terms, leading them to call on the police more often as a first resort. Alternatively, this tendency to stigmatise mental illness might hinder help-seeking to the point where a crisis ensues, and the risk of police 
involvement and formal intervention is substantially increased (Morgan et al, 2005).

\section{Late presentation and pathways to care}

Bhui et al (2003) observed that Black patients were the most likely to present in a crisis, so that their first point of contact with mental health services is an on-call psychiatrist. Other studies concluded that the failure of community services to engage mentally ill African-Caribbean men had resulted in a repeated pattern of presentation through the criminal justice system (Bhui et al, 1998), and increased admissions to forensic units (Coid et al, 2000). These studies suggested that the accelerated pattern of offending behaviour was related to the onset of severe mental illness.

The late presentation may have been because a high proportion of Black males were single and living in more socio-economically deprived circumstances, leading to a more significant degree of social isolation (Bhui et al, 1998). Another explanation has been the failure to recognise mental illness by healthcare professionals, the patient or their family until it has become more severe (Bhui \& Bhugra, 2002).

\section{Lack of GP involvement}

Bhui \& Bhugra (2002) suggested that the police involvement in admissions or readmissions of Black people might be explained by lack of general practitioner (GP) involvement, rather than the ethnic origin of the patients. Black patients were the least likely to be recognised as having a mental disorder in primary care. Black people who had seen their GP were less likely to be referred to specialist services compared with White and South Asian patients (Bhui et al, 2003). However, among patients known to their GP because of a recognised mental health problem, Black patients were more likely to be found in specialist services. This may reflect a mismatch between the Black patient's cultural expression of distress, and the signs and symptoms sought by the clinician as manifestations of psychiatric illness. For example, Ndetei \& Vadher (1984) found that West African patients with schizophrenia reported visual hallucinations more commonly than patients from other cultural backgrounds.

\section{Lack of satisfaction with and mistrust of services}

Cochrane \& Sashidharan (1996) reported that some ethnic groups complained of more coercive treatment by and adverse experiences of mental health services. The excessive use of compulsory admission could account for the dissatisfaction and avoidance of services (Bhui et al, 2003), thus setting up a vicious cycle of involuntary admissions. Second-generation African-Caribbean patients have reported feeling less satisfied with services compared with older African-Caribbean and White patients (Sharpley et al, 2001). Sharpley et al found that the number of previous admissions significantly predicted lack of satisfaction in the African-Caribbean group.

\section{Migration}

The motivations of individuals who migrate are widely different - to avoid persecution, because of dissatisfaction with political regimes, and in search of a better education or economic opportunity. People moving country as part of a wider group may not share the same motives or lifestyle. The experience of migration can be positive or negative. Its impact on mental health is dependent on many factors, including age and gender, as well as economic and cultural factors in the country of reception (Sharpley et al, 2001). There is evidence that migration itself might increase levels of psychosis. Bruxner et al (1997) demonstrated the persistence of high rates of presentation of psychotic disorders among people born in Eastern Europe, many years after migration to Australia.

\section{Historical factors: slavery and racism}

African slaves first arrived in the UK in the 1550s. In the middle of the 18th century Black slaves formed 3\% of the British population. After 1948 under the British Nationality Act, large groups of post-war economic migrants came from the poorer commonwealth territories, including the Caribbean, and were allowed to enter Britain freely to find work. They had emigrated from their native countries to help with labour shortages. They experienced culture shock, alienation, racism and deprivation.

Franz Fanon (1963), a Black French Caribbean psychiatrist who trained in Lyon and practised in Algiers, pointed out the psychological effects of colonialism as one of the enduring disabling legacies bequeathed to natives by their colonial masters. He argued that the Black experience could not be separated from their respective histories as recipients of Black colonisation. Over the past few hundred years, many stereotypes have developed of Black people as an inferior race.

It may be argued that historical trauma can have an impact on the collective psyche of an ethnic group. Black slavery had the impact of forcibly removing Africans from their native lands, destroying their histories, their cultural identity and forcing them into 
submitting to their White masters in a foreign land. The detention and treatment of a Black AfricanCaribbean patient can inadvertently replicate this traumatic experience. This could in part explain the distrust of psychiatric services and other White authority figures by this cultural group.

Racism is a form of discrimination that has its roots in the belief that groups should be treated differently because of phenotypic differences. Racism is widespread in the UK (Chakraborty \& McKenzie, 2002). Racism has an effect on the victim's physical, social and psychological environment. It compounds the effects of gender and social class. In the USA, the experience of racism has been shown to influence the perception of self and of community (Sharpley et al, 2001). Research has not linked racism aetiologically to psychotic illness, but thwarted aspirations have been linked to psychological stress and to deterioration in psychological well-being, although not as yet to mental illness (Sharpley et al, 2001).

Coid et al (2000) challenged the view that racism had a role to play in increased rates of detention of Black men. Their study demonstrated that first admission rates to forensic units for half of England and Wales were 5.6 times higher among Black men than among White men, whereas rates for Asian men were half those for White men. Black women's admission rates were 2.9 times higher than those of White women, but Asian women had admission rates that were one-third those of White women.

\section{Institutional racism in psychiatry}

There has been increasing discussion about institutional racism in public bodies in the UK since the Macpherson report into the death of Stephen Lawrence (Chakraborty \& McKenzie, 2002).

The roots of racism within psychiatric care can be traced to the conception of the theoretical framework of what constitutes modern psychiatry (Littlewood \& Lipsedge, 1984; Fernando, 1991). Fernando (1991) argued that since psychiatry developed in the West when a belief in the racial superiority of Whites was rife, this false ideology became incorporated into psychiatry as a discipline. He concluded that the emphasis on individualised pathology and insufficient attention paid to social factors such as race and culture rendered psychiatry a racist institution.

Others have suggested that psychiatrists have carried their own cultural assumptions (derived from the dominant Western culture) without apparently being aware of this and have developed a system of thinking and acting based on these Western cultural ideas. Contemporary psychiatry has been imposing these Western culturally constructed ideas in communities that have very different models of understanding mental health problems and what to do about them (Tyrer, 2005).

\section{The ethnic background of psychiatrists}

According to the Royal College of Psychiatrists' (2005) census of psychiatric staffing, nearly 1 in 3 consultant psychiatrists in locum and substantive posts in England, and 1 in 5 in Wales, come from Black or minority ethnic backgrounds. Nearly $4 \%$ of consultant psychiatrists in England and 2.5\% in Wales come from a Black ethnic group. Among junior doctors the proportion of trainees from Black or minority ethnic groups is still greater. This would indicate that if psychiatrists are racially biased, this bias is not necessarily by White psychiatrists, lending credence to the suggestion that if there is racism within psychiatry it is an inherent part of psychiatry as a conceptual understanding.

\section{Lack of cultural sensitivity}

Several researchers have suggested that culturally sanctioned and acceptable distress experiences may wrongly attract pathological explanations from professionals. For instance, first-rank symptoms of schizophrenia may not have the same diagnostic significance across cultures (Bhui \& Bhugra, 2002). Similarly, the assignation of pathological significance to 'paranoid beliefs' among African and West Indian groups may be flawed. Other researchers (Littlewood \& Lipsedge, 1984) have suggested that paranoia and beliefs with a religious content are more common among West Indians and West Africans. Johns et al (2002) has suggested that the same may be true of hallucinatory experiences among Black adolescents.

Robertson et al (2000) found that half the Black patients in their study believed that their treatment and diagnosis might have been different had they been in contact with a member of staff who understood the experiences of a Black person. However, Lewis et al (1990) reported that British psychiatrists who were asked to diagnose a case vignette of psychotic illness, where the 'race' of the vignette were varied, did not overdiagnose schizophrenia in the African-Caribbean case. In a study by Hickling et al (1999), a group of patients diagnosed by White British psychiatrists was then rediagnosed by a Jamaican psychiatrist. The White British psychiatrists diagnosed $55 \%$ of the Black patients as having schizophrenia and the Jamaican psychiatrist $52 \%$. However, interestingly, the diagnoses of the British psychiatrists and the African-Caribbean psychiatrist agreed in only $55 \%$ of cases. 


\section{Socio-economic deprivation}

Any psychiatric patient, regardless of their cultural group, who does not have a confidant or GP to support them is more likely to be admitted through the police (Cole et al, 1995). The greater social isolation characteristic of people with schizophrenia means that they tend to be admitted late, having failed to recognise their own illness.

After making adjustments for first-contact admissions, past admissions and marital status, Owens et al (1991) still found an excess of admissions among Black people. Similarly, Bhui et al (1998) found that African-Caribbean men were more likely to be remanded into police custody despite more stable housing conditions and more favourable indices of lifetime criminality, substance misuse and violence. A more recent study (Morgan et al, 2005) found that both African-Caribbean and Black African patients were significantly more likely to live alone than White British patients; and African-Caribbean patients were more likely to be single than White British patients. In this study, there was no difference between African-Caribbean and White patients in the levels of family involvement in the pathway to care, although White patients were more likely to seek help of their own accord.

Morgan et al (2005) found that in south-east London African-Caribbean patients were significantly less likely than White British, other White and Black African groups to be educated beyond school level. Of particular note was the small number of African-Caribbean patients who had been educated to university level. Unemployment is higher in all the minority ethnic groups when compared with the White British group, although this reached statistical significance only for the African-Caribbean group. Sharpley et al (2001) mention studies which have found that children who later develop schizophrenia have lower mean IQs, more personality and interpersonal problems than their peers, excess of conduct disorder and lower educational achievement. Thus it may be relevant that African-Caribbean children in England achieve less academically and have higher rates of diagnosed intellectual disability (currently termed learning disability in UK health services) compared with the population as a whole.

Coid et al (2000) suggested that socio-economic disadvantage was unlikely to be the primary cause of the variations between ethnic groups. Patients from African-Caribbean and Asian subgroups both originated from more socio-economically deprived areas, but treated prevalence rates were higher in African-Caribbeans, and lower in Asians, than in Whites. Similarly, patterns of criminal behaviour showed even greater differences when the two subgroups were compared.
Box 2 The association between inner-city living and schizophrenia

Social factors

- More stressful life events

- Social isolation

- Overcrowding

- Overstimulation

- Higher crime levels

- Lower socio-economic class

Physical factors

- Greater exposure to air-borne and other pollutants

Biological factors

- Lower birth weight

- More prenatal, maternal and other infections

(Sharpley et al, 2001)

Sharpley et al (2001) suggested that AfricanCaribbean patients with psychosis perceive adverse life events as part of a continuous pattern of adversity directed at them because of their ethnicity. African-Caribbeans may be more at risk of developing this particular style of attribution because their experience of social disadvantage and racial discrimination in the UK results in: (a) a need to question self-perception and identity; and (b) more threat in their everyday social life.

\section{Living in inner cities}

Minority ethnic groups are most likely to live in inner cities (Harrison, 2002). This is of significance since there is a high correlation between the use of medium secure beds and levels of social deprivation within the population, particularly the rate of unemployment (Guite \& Field, 1998). In keeping with this, the relative use of medium secure units in greater London in 1996 was nearly twice that of England and Wales as a whole. The association between deprived, run-down inner-city areas and a high rate of psychiatric admissions in general and schizophrenia in particular is well known. This may not simply be a consequence of social drift or social residue (Box 2) and it adds to the claim that being born or brought up in the city increases the risk of schizophrenia (Sharpley et al, 2001).

\section{What is the solution?}

\section{Government action}

In recent years a number of government initiatives have been introduced to tackle the problem 


\section{Box 3 Government initiatives to tackle} problem

- Race Relations (Amendment) Act 2000

- Delivering Race Equality in Mental Health Care (DRE; Department of Health, 2005)

- The Black and minority ethnic (BME) mental health programme (http://www. dh.gov.uk/en / Policyandguidance / Healthandsocialcaretopics/Mentalhealth/ BMEmentalhealth/index.htm)

- Count Me In Census (http://www.health carecommission.org.uk/nationalfindings / nationalthemedreports / mentalhealth / mentalhealthreports.cfm/cit_id/445)

(Box 3). The Race Relations (Amendment) Act (2000) imposes on public authorities a new statutory duty to promote racial equality. This encompasses a general duty to eliminate unlawful racial discrimination and promote equality of opportunity and good race relations. In 2003, the Department of Health published Inside Outside: Improving Mental Health Services for Black and Minority Ethnic Communities in England (Sashidharan, 2003). This outlines the focus for change under three main headings:

- reducing and eliminating ethnic inequalities in mental health service experience and outcome

- developing the workforce

- engaging the community and building capacity.

Delivering Race Equality in Mental Health Care (DRE; Department of Health, 2005) is an action plan for achieving equality and tackling discrimination in mental health services in England for all people of Black and minority ethnic (BME) status, including those of Irish or Mediterranean origin and Eastern European migrants. The programme is based on three building blocks first proposed in the consultation version of DRE:

- more appropriate and responsive services: achieved through action to develop organisations and the workforce, to improve clinical services and to improve services for specific groups, such as older people, asylum seekers and refugees, and children

- community engagement: delivered through healthier communities and by action to engage communities in planning services, supported by 500 new 'community development workers'
- better information: from improved monitoring of ethnicity, better dissemination of information and good practice, and improved knowledge about effective services. This will include a new regular census of mental health patients.

The BME mental health programme is an integral part of the Department of Health's wider programme for race equality in the NHS and is led by Professor Kamlesh Patel, Head of the Centre for Ethnicity and Health at the University of Central Lancashire and Chair of the Mental Health Act Commission.

The second Count Me In Census was carried out in 2006 (Mental Health Act Commission et al, 2007). The purpose of these annual censuses is to help those who provide mental health and learning disability services to ensure that services are culturally relevant and appropriate, and to provide improved information on service delivery - one of the three building blocks of DRE (Department of Health, 2005). The data will provide important information on which to base service improvement. However, as mentioned above, there is a need for clearer definition of ethnic grouping and for more extensive data collection in this area (Audini \& Lelliott, 2002; Bhui, 2002; Harrison, 2002). ${ }^{+}$

\section{Focused support}

Advocacy groups continue to play a part in tackling the problem. Cliff Prior, past Chief Executive of Rethink, spoke in May 2006, at the All Parliamentary Group for Mental Health, about the need for a thorough race equality impact assessment on the whole (new Mental Health) Act (Jones, 2007). (The Commission for Racial Equality (2007) states that the purpose of a race equality impact assessment is to work out how a policy or legislative proposal will affect people from different racial groups.) More locally, there are organisations that have existed for many years to meet the needs of Black men (such as the African-Caribbean Mental Health Association, which offers services throughout the UK).

Within NHS trusts, and more specifically mental health services, there is now a clear stated aim to provide diverse and equal services. Equal opportunities legislation applies to candidates who apply for NHS jobs. The staff group within mental health services is generally multicultural, particularly within London. The Antenna Outreach Service in north London is an example of a mental health service set up solely for the needs of young Black men.

+See also correspondence on p. 394, this issue. Ed. 


\section{Education and training}

Education and training are vital in tackling the problem. Bachelor degrees in anthropology are available. There are Masters degrees in transcultural psychiatry, medical anthropology, and culture and health. Within NHS trusts, diversity and equality training is available. In its Race Equality Action Plan, the Royal College of Psychiatrists (2003) lists as one its tenets 'Ensuring that core training and education of members and trainees includes capability in race and culture issues'. Bhugra \& Bhui (2001) have called for training of professionals to include the socio-demographic profile of minority ethnic groups, studies on the impact of racism and antiracism, cultural comparisons, culturally determined beliefs, idioms of distress and alternative healing. They further stress the need for such training as part of continuing professional development for all psychiatrists.

\section{Research}

There are many research implications in this area. In a discussion of minority ethnic groups and the Mental Health Act, Harrison (2002) calls for research of appropriate study design and sufficient sample size that includes service users from different groups. He also comments on the need for qualitative measures to be further explored, for example the examination of cultural factors in access to care and racist attitudes operating in the service. He wonders what culturally sensitive services would look like and warns of the risks of developing wide-ranging programmes ahead of a knowledge base. Coid et al (2000) state that research should concentrate on recognition of high-risk subgroups of mentally ill people within all ethnic groups, with development of new measures to improve engagement in aftercare. Morgan et al (2005) consider the usefulness of sociological and anthropological models in the study of illness behaviour, and comment on the need to break the cycle of negative experiences, coercion, disengagement and relapse.

\section{Conclusions}

The ethnic bias in the application of the Mental Health Act 1983 results from the combination of increased rates of psychotic illness, and late presentation to psychiatric services, by Black patients. The excess of psychosis appears to result not from a biological predisposition to the illness, but from the interplay of environmental factors, and is therefore potentially preventable. Early identification of psychosis can be affected by improving community services in inner cities where many of the Black community in Britain reside. Research and funding directed towards this goal will not only benefit the Black community in Britain but lead to a greater understanding of the aetiology and prevention of psychosis as a disease entity.

\section{Declaration of interest}

None.

\section{References}

Aspinall, P. J. (2006) Informing progress towards race equality in mental healthcare: is routine data collection adequate? Advances in Psychiatric Treatment, 12, 141-151.

Audini, B. \& Lelliott, P. (2002) Age, gender and ethnicity of those detained under Part II of the Mental Health Act 1983. British Journal of Psychiatry, 180, 222-226.

Bhugra, D. \& Bhui, K. (2001) Cross-Cultural Psychiatry: A Practical Guide. Arnold.

Bhui, K. (2002) (ed.) Racism and Mental Health: Prejudice and Suffering. Jessica Kingsley.

Bhui, K. \& Bhugra, D. (2002) Mental illness in Black and Asian ethnic minorities: pathways to care and outcomes. Advances in Psychiatric Treatment, 8, 26-33.

Bhui, K., Brown, P., Hardie, T., et al (1998) African-Caribbean men remanded to Brixton Prison. Psychiatric and forensic characteristics and outcome of final court appearance. British Journal of Psychiatry, 172, 337-344.

Bhui, K., Stansfeld, S., Hull, S., et al (2003) Ethnic variations in pathways to and use of specialist mental health services in the UK. Systematic review. British Journal of Psychiatry, 182, 105-116.

Bruxner, G., Burvill, P., Fazio, S., et al (1997) Aspects of psychiatric admissions of migrants to hospitals in Perth, Western Australia. Australian and New Zealand Journal of Psychiatry, 31, 532-542.

Caspi, A., Moffit, T. E., Cannon, M., et al (2005) Moderation of the effect of adolescent-onset cannabis use on adult psychosis by a functional polymorphism in the catechol-o-methyltransferase gene: longitudinal evidence of a gene $x$ environment interaction. Biological Psychiatry, 57, 1117-1127.

Chakraborty, A. \& McKenzie, K. (2002) Does racial discrimination cause mental illness? British Journal of Psychiatry, 180, 475477.

Cochrane, R. \& Sashidharan, S. P. (1996) Mental Health and Ethnic Minorities: A Review of the Literature and Implications for Services (NHS Centre for Reviews and Dissemination/Social Policy Research Unit. Report 5). University of York.

Coid, J. W., Kahtan, N., Gault, S., et al (2000) Ethnic differences in admissions to secure forensic psychiatric services. British Journal of Psychiatry, 177, 241-247.

Cole, E., Leavey, G., King, M., et al (1995) Pathways to care for patients with a first episode of psychosis. A comparison of ethnic groups. British Journal of Psychiatry, 167, 770-776.

Commission for Racial Equality (2007) Race Equality Impact Assessment: A Step-by-Step Guide. CRE. http://www.cre.gov. uk/duty/reia/index.html

Department of Health (2005) Delivering Race Equality in Mental Health Care: An Action Plan for Reform Inside and Outside Services and the Government's Response to the Independent Inquiry into the Death of David Bennett. Department of Health.

Fanon, F. (1963) The Wretched of the Earth (trans. C. Farrington). Grove Weidenfeld.

Fernando, S. (1991) Mental Health, Race and Culture. Macmillan/ Mind

Guite, H. \& Field, V. (1998) Services for mentally disordered offenders. In London's Mental Health (eds S. Johnson, S. Ramsay, G. Thornicroft, et al), pp. 99-117. King's Fund.

Harrison, G. (2002) Ethnic minorities and the Mental Health Act. British Journal of Psychiatry, 180, 198-199. 
Hickling, F. W., McKenzie, K., Mullen, R., et al (1999) A Jamaican psychiatrist evaluates diagnosis at a London psychiatric hospital. British Journal of Psychiatry, 175, 283-285.

Johns, L. C., Nazroo, J. Y., Bebbington, P., et al (2002) Occurrence of hallucinatory experiences in a community sample and ethnic variations. British Journal of Psychiatry, 180, 174-178.

Jones, L. (2007) Mental Health. All Party Parliamentary Group on Mental Health: Annual Report: 2005/06. http:/ / www.lynnejones. org.uk/d0515.2005-6.annual.htm

Lewis, G., Croft-Jeffreys, C. \& David, A. (1990) Are British psychiatrists racist? British Journal of Psychiatry, 157, 410-415.

Littlewood, R. \& Lipsedge, M. (1984) Aliens and Alienists. Unwin.

Mental Health Act Commission, Care Services Improvement Partnership, National Institute for Mental Health in England, et al (2007) Count Me In: Results of the 2006 National Census of Inpatients in Mental Health and Learning Disability Services in England and Wales. Commission for Healthcare Audit and Inspection.

Morgan, C., Mallett, R., Hutchinson, G., et al (2005) Pathways to care and ethnicity. 2: Source of referral and help-seeking. Report from the ÆSOP study. British Journal of Psychiatry, 186, 290-296.

Ndetei, D. M. \& Vadher, A. (1984) A cross-cultural study of the frequencies of Schneider's first rank symptoms of schizophrenia. Acta Psychiatrica Scandinavia, 70, 540-544.

Owens, D., Harrison, G. \& Boot, D. (1991) Ethnic factors in voluntary and compulsory admissions. Psychological Medicine, 21, 185-196.

Pipe, R., Bhat, A., Matthews, B., et al (1991) Section 136 and African/Afro-C Caribbean minorities. International Journal of Social Psychiatry, 37, 14-23.

Robertson, D., Sathyamoorthy, G. \& Ford, R. (2000) Asking the right question. Community Care, 163, 24-25.

Royal College of Psychiatrists (2003) Equality and Diversity. Royal College of Psychiatrists. http:/ / www.rcpsych.ac.uk/college/ equalityanddiversity.aspx? theme $=$ print

Royal College of Psychiatrists (2005) 13th Annual Census of Psychiatric Staffing 2005. Royal College of Psychiatrists. http:// www.rcpsych.ac.uk/training/census.aspx

Rwegellera, G. G. (1980) Differential use of psychiatric services by West Indians, West Africans and English in London. British Journal of Psychiatry, 137, 428-432.

Sashidharan, S. P. (2003) Inside Outside: Improving Mental Health Services for Black and Minority Ethnic Communities in England. Department of Health.

Sharpley, M. S., Hutchinson, G., Murray, R. M., et al (2001) Understanding the excess of psychosis among the African-Caribbean population in England. Review of current hypotheses. British Journal of Psychiatry, 178 (suppl. 40), s60-s68.

Thornicroft, G., Strathdee, G., Phelan, M., et al (1998) Rationale and design. PRiSM Psychosis Study I. British Journal of Psychiatry, 173, 363-370.

Tyrer, P. (2005) Racism in psychiatry - Author's reply. British Journal of Psychiatry, 186, 540.

\section{MCQs}

1 One of the three building blocks of Delivering Race Equality is:

a assessing patients' cultural appraisal of problems

$b$ ensuring that core training and education of members and trainees includes capability in race and culture issues c more appropriate and responsive services

d decreased focus on data systems

e SureStart initiatives.

2 Education and training initiatives that might help tackle the problem include:

a a Masters degree in culture and mental health

$\mathrm{b}$ participating in an audit on physical health

c a Masters degree in mental health law

d setting up a crisis resolution and home treatment team

e workplace-based assessment.

3 The incidence of schizophrenia in the UK is increased in:

a South Asians

$\mathrm{b}$ women

c African-Caribbeans

d all migrant groups

e those over 25 .

4 Of the following, the most likely reason for the ethnic bias in application of the Mental Health Act is:

a biological predisposition to schizophrenia

b alcohol use

c maternal influenza rates higher in some ethnic groups

d misuse of steroids

e lack of cultural understanding.

5 Cultural awareness may be increased by:

a cultural education

b cultural stereotyping

c the Race Relations Act

d linguistic training

e compulsory treatment.

\section{MCQ answers}

$\begin{array}{lllllll}1 & & 2 & & 3 & 4 & 5 \\ \text { a F } & \text { a T } & \text { a F } & \text { a F } & \text { a T } \\ \text { b F } & \text { b F } & \text { b F } & \text { b F } & \text { b F } \\ \text { c T } & \text { c F } & \text { c T } & \text { c F } & \text { c F } \\ \text { d F } & \text { d F } & \text { d F } & \text { d F } & \text { d F } \\ \text { e F } & \text { e F } & \text { e F } & \text { e T } & \text { e F }\end{array}$

